Check for updates

Cite this: RSC Adv., 2019, 9, 13878

Received 3rd April 2019

Accepted 26th April 2019

DOI: 10.1039/c9ra02525a

rsc.li/rsc-advances

\title{
Synthesis of novel natural product-like diaryl acetylenes as hypoxia inducible factor-1 inhibitors and antiproliferative agents $\uparrow$
}

\author{
Shisheng Wang, (D) ab Liqiang Liu, ${ }^{a}$ Xiuhan Guo, (D) ab Guangzhe Li, (D)*ab Xu Wang, ${ }^{a}$ \\ Huijuan Dong, ${ }^{a}$ Yueqing $\mathrm{Li}^{\mathrm{ab}}$ and Weijie Zhao ${ }^{\mathrm{ab}}$
}

\begin{abstract}
The selaginellin derivatives are a type of novel natural pigments with an unusual alkynyl phenol skeleton from the genus Selaginella. Some of these natural compounds were previously reported to show important bioactivities, including anticancer activity, cardiovascular protection and phosphodiesterase-4 inhibition. We designed and synthesized fifteen biphenyl-containing diaryl acetylene derivatives mimicking the skeleton of natural alkynyl phenols. In MTT assay in cancer cells, compounds $1 \mathrm{c}, 2 \mathrm{~d}, \mathbf{2 g}$, $2 \mathrm{~h}, 2 \mathrm{i}$ and $2 \mathrm{j}$ exhibited potent antiproliferative activity. The evaluation of Hypoxia Inducible Factor-1 (HIF1) pathway inhibitory activity in dual luciferase assay demonstrated that most tested compounds exhibited moderate to good activities. Compounds $1 \mathrm{a}, 2 \mathrm{f}$ and $2 \mathrm{~h}$ displayed high HIF-1 inhibitory activities and relatively low cytotoxicity, demonstrating great potential as HIF-1 inhibitors. These results afford a new strategy for the discovery of new HIF-1 inhibitors and anti-proliferative agents from natural or synthetic diaryl acetylene derivatives.
\end{abstract}

\section{Introduction}

Natural products and their synthetic derivatives have served as a consistent source of valuable new drug leads for centuries, and natural products with bioactive pharmacophores are biologically validated starting points for the development of new drugs. ${ }^{1}$ In the last decade, a type of novel natural pigment with an unusual alkynyl phenol skeleton has been successively isolated from the genus Selaginella, mainly from S. tamariscina and S. pulvinata which are the two qualified species listed in Chinese Pharmacopoeia and used as traditional Chinese medicines for the treatment of dysmenorrhea, abdominal mass and traumatic injury. The pharmacological investigations of the genus Selaginella have revealed that it has anticancer, antivirus, antioxidant and anti-inflammatory activities. ${ }^{2}$ The phytochemical investigations of the genus Selaginella have led to the identification of more than forty natural alkynyl phenols hitherto, including selaginellin, ${ }^{3}$ selaginellins $\mathrm{A}-\mathrm{W},{ }^{\mathbf{4}-19}$ selariscinins $\mathrm{A}-\mathrm{D},{ }^{\mathbf{1 4 , 1 7}}$ and selaginpulvilins A-L. ${ }^{20-25}$ All these natural products possess unique skeletons characterized by biphenyl-containing diaryl acetylene, as shown in Fig. 1.

\footnotetext{
${ }^{a}$ Department of Pharmacy, School of Chemical Engineering, Dalian University of Technology, Dalian 116023, China. E-mail: liguangzhe@dlut.edu.cn

${ }^{b}$ State Key Laboratory of Fine Chemicals, Dalian University of Technology, Dalian 116023, China

$\uparrow$ Electronic supplementary information (ESI) available: Spectral data of synthetic compounds. See DOI: $10.1039 / \mathrm{c} 9 \mathrm{ra} 02525 \mathrm{a}$
}

The biological activities of these alkynyl phenol compounds have been demonstrated to involve hypoglycemic, ${ }^{\mathbf{1 4}}$ antiinflammatory, ${ }^{26}$ and anti-oxidant ${ }^{27}$ activity, cardiovascular protection, ${ }^{28}$ anticancer effects, ${ }^{9}$ and neuroprotective effects. ${ }^{18,29,30}$ Selaginellin and selaginellins A, C, M, N, O, Q have been reported to be cytotoxic against U251, HeLa, MCF-7 and BGC-823 tumor cells. ${ }^{\text {9-11 }}$ Selaginpulvilins A-L, with an unprecedented 9,9-diphenyl-1-(phenylethynyl)-9H-fluorene skeleton, exhibit remarkable phosphodiesterase-4 inhibitory activity with $\mathrm{IC}_{50}$ of $0.011-1.38 \mu \mathrm{M}^{20,22,25}$ The previous work in our laboratory on the bioactive constituents from the genus Selaginella revealed selaginellins A and B were moderately cytotoxic against H322 cell, and selaginellin A displayed inhibitory activity on hypoxia inducible factor-1 (HIF-1) transcription in dual luciferase reporter assay (unpublished).

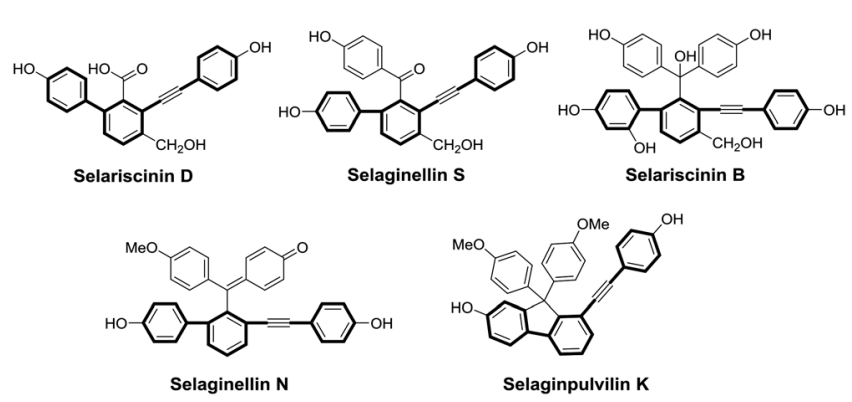

Fig. 1 Selected examples of natural diaryl acetylene compounds from the genus Selaginella. 
HIF-1 is a central regulator involved in detection and adaption to cellular oxygen stress through regulation of the hypoxic transcriptional program in angiogenesis, erythropoiesis, and metabolism. ${ }^{31}$ The HIF-1 pathway is involved in many diseases, including anemia, ischemia, most tumors, and other hypoxicischemic diseases, making HIF-1 an attractive target for therapeutic application. ${ }^{32}$ A considerable proportion of solid tumors are induced by hypoxia which results in overexpression of the HIF-1 pathway. Moreover, overexpression of the HIF-1 pathway has been correlated with poor prognosis, invasive tumor growth, and resistance to radiation for tumor patients. ${ }^{33}$ Therefore, the inhibition of HIF- 1 has been identified as an effective therapeutic strategy for various solid tumors. ${ }^{34}$

The unique skeletons associated with important bioactivities of this family of alkynyl phenols have attracted great attention of scientists from fields of organic synthesis and medicinal chemistry. Up to now, the reports on the total synthesis of natural alkynyl phenols are rare and all focus on the diarylfluorene derivatives selaginpulvilins, ${ }^{21,23-25}$ whereas the total synthesis of selaginellins and selariscinins has not been reported yet. In our effort to develop synthetic method for selaginellins, we achieved the precursors of selaginellin $\mathrm{N}$ (1a-1d) with the skeleton of selariscinin $\mathrm{D}$ and selaginellin $\mathrm{S}$. The difficulty in the synthesis of selaginellins with moiety of benzyl para-quinone methide is considered to result from the large steric hindrance of polycyclic skeleton. Considering the unique diaryl acetylene skeleton as a good privileged structure, we designed and synthesized a series of non-natural diaryl acetylene derivatives (2a-2j) analogous to selaginellins but with less steric hindrance. Herein we report the synthesis of this family of diaryl acetylene derivatives, their cytotoxic activity against tumor cells and HIF-1 inhibitory activity.

By analyzing the structures of selaginellin and its reported derivatives, P. F. Tu et al. proposed a potential biosynthetic pathway of selaginellin and its derivatives. ${ }^{35}$ We compared the different skeletons of natural alkynyl phenols as displayed in Fig. 1 and presumed that the formation of selaginellin $\mathrm{N}$ analogues might undergo the intermediates of selariscinin D analogues, selaginellin $\mathrm{S}$ analogues and selariscinin $\mathrm{B}$ analogues successively. Based on this presumption, a retrosynthetic analysis of selaginellin $\mathrm{N}$ was established as shown in Scheme 1, where selariscinin D analogues were synthesized
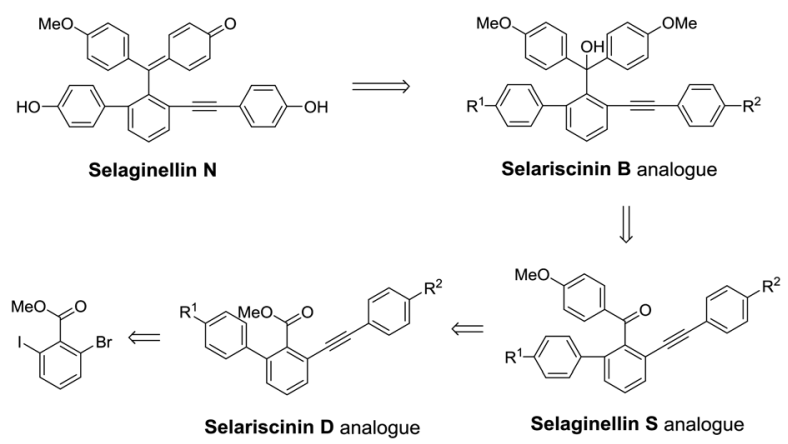

Scheme 1 Retrosynthetic analysis of diaryl acetylene compounds. starting with halogenated benzoate via the Suzuki coupling and Sonogashira reaction.

\section{Results and discussion}

\subsection{Chemistry}

With the aim to synthesize selaginellin $\mathrm{N}$, we first synthesized 1a using $o$-bromobenzoic acid as the starting material via iodization, methyl esterification, regioselective Suzuki coupling reaction and Sonogashira reaction (Scheme 2). Using $\mathrm{THF}-\mathrm{H}_{2} \mathrm{O}$ as the solvent in Suzuki reaction, compound $\mathbf{6}$ was obtained under mild condition with a better yield than reported. ${ }^{24}$ Compound 1a has a skeleton similar to selariscinin $\mathrm{D},{ }^{15}$ which exhibited stimulatory effect on glucose uptake in 3T3-L1 adipocyte cells and potent inhibitory effect against PTP1B.

We attempted to synthesize selaginellin $\mathrm{N}$ through the demethylation and dehydration of triphenyl methol intermediate 1f. However, the nucleophilic addition of 1a with 4methoxyphenyl bromide under the presence of $n$-butyllithium produced the diphenyl ketone 1c instead of triphenyl methol (Scheme 3). The steric hindrance of 1c is presumably the dominated factor to prevent the further reaction to produce triphenyl methol. We tried using the more reactive acyl

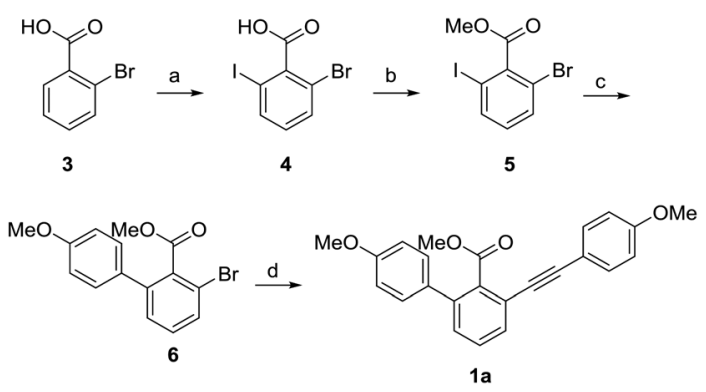

Scheme 2 Synthesis of compound 1a. Reagents and conditions: (a) $\mathrm{Pd}(\mathrm{OAc})_{2}, \mathrm{NIS}, \mathrm{DMF}, 100{ }^{\circ} \mathrm{C}, 12 \mathrm{~h}, 90 \%$; (b) $\mathrm{K}_{2} \mathrm{CO}_{3}, \mathrm{CH}_{3}$ l, acetone, $40{ }^{\circ} \mathrm{C}, 5 \mathrm{~h}, 100 \%$; (c) $\mathrm{Na}_{2} \mathrm{CO}_{3}, 4$-methoxyphenylboronic acid, $\mathrm{PdCl}_{2}\left(\mathrm{PPh}_{3}\right)_{2}, \mathrm{THF} / \mathrm{H}_{2} \mathrm{O}=1: 1,60{ }^{\circ} \mathrm{C}, 8 \mathrm{~h}, 82 \%$; (d) 4-methoxyphenylacetylene, $\mathrm{Cul}, \mathrm{PdCl}_{2}\left(\mathrm{PPh}_{3}\right)_{2}, \mathrm{PPh}_{3}, \mathrm{Et}_{3} \mathrm{~N}, \mathrm{DMF}, 120^{\circ} \mathrm{C}, 12 \mathrm{~h}$, $48 \%$.

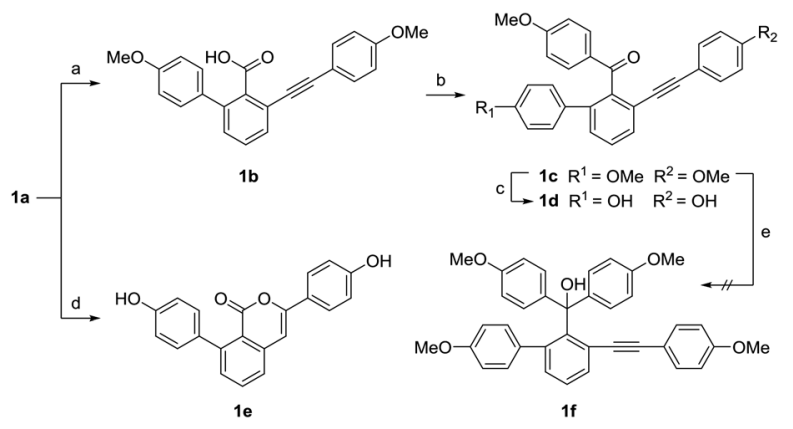

Scheme 3 Synthesis of compounds $1 \mathrm{~b}-1 \mathrm{e}$. Reagents and conditions: (a) $\mathrm{NaOH}, \mathrm{CH}_{3} \mathrm{OH} / \mathrm{H}_{2} \mathrm{O}=5: 1,80{ }^{\circ} \mathrm{C}, 8$ h, $77 \%$; (b) $\mathrm{SOCl}_{2}, \mathrm{CH}_{2} \mathrm{Cl}_{2}$, r.t. $2 \mathrm{~h}$, then $n$-BuLi, 1-bromo-4-methoxybenzene, THF, $-83^{\circ} \mathrm{C}, 2 \mathrm{~h}, 38 \%$; (c) $\mathrm{BBr}_{3}, 0{ }^{\circ} \mathrm{C}, 30 \mathrm{~min}, 17 \%$; (d) $\mathrm{BBr}_{3}, 0{ }^{\circ} \mathrm{C}, 2 \mathrm{~h}, 33 \%$. (e) $n$-BuLi, 1bromo-4-methoxybenzene, THF, $-83-0{ }^{\circ} \mathrm{C}, 2 \mathrm{~h}$, not detected. 
chloride, which was prepared via the hydrolysis and chlorination of 1a. As a result, 1c was still yielded as the major product and no product of triphenyl methol was detected. Although the efforts to synthesize selaginellin $\mathrm{N}$ failed, the diphenyl ketones 1c and 1d are still important products since they bear the same skeleton with selaginellin $\mathrm{S}$, which showed inhibitory effects against hepatitis $\mathrm{B}$ virus gene expression and replication. ${ }^{\mathbf{1 6}}$ During the demethylation of $\mathbf{1 a}$ with boron tribromide, an unexpected isocoumarin 1e was obtained as the main product.

In view of the high steric hindrance in natural selaginellins, we designed and synthesized a series of selaginellin analogs $(\mathbf{2 a}-\mathbf{2} \mathbf{j})$ with a different attached position of 4-methoxyl phenylacetylene group (Scheme 4). Using the similar synthetic approach of 1a, 2a was obtained with a high yield starting with $o$-iodobenzoic acid via bromination, methyl esterification, regioselective Suzuki coupling and Sonogashira reaction. Compared with the yield of $\mathbf{1 a}$ in Sonogashira reaction, the yield of $\mathbf{2 a}$ was greatly increased due to less side reaction between meta-substituted carboxylic ester and alkynyl. ${ }^{36}$

In the next nucleophilic addition of 2a, using 4-methoxyphenylmagnesium bromide as the nucleophilic regent yielded a diphenyl ketone product 2c, whereas using 4-methoxyphenyl bromide under the presence of $n$-butyllithium produced the triphenyl methol 2e along with a side product $2 \mathrm{f}$ (Scheme 5). As we expected, the less steric hindrance of $2 \mathbf{a}$ than that of $1 \mathbf{a}$ allowed the production of triphenyl methol under the same conditions.

As Scheme 6 described, the demethylation of $2 \mathbf{e}$ with $\mathrm{BBr}_{3}$ under different conditions gave three different products. By controlling the reaction temperature at $-83{ }^{\circ} \mathrm{C}$ and using small equivalents of $\mathrm{BBr}_{3}$, we obtained two demethylation products $2 \mathrm{~g}$ and $2 \mathbf{h}$. When the reaction temperature was set at $0{ }^{\circ} \mathrm{C}$, the diarylfluorene derivative $2 \mathbf{i}$, the analog of selaginpulvilin $\mathrm{K}$, was yielded, probably from the Friedel-Crafts reaction under the catalysis of boron tribromide. In order to hydrolyze more methyl groups, we used excessive equivalents of $\mathrm{BBr}_{3}$ and slowly raised the reaction temperature from $-83{ }^{\circ} \mathrm{C}$ to $0{ }^{\circ} \mathrm{C}$. As we expected, the demethylation and dehydration occurred simultaneously to produce the benzyl para-quinone methide derivative $2 \mathbf{j}$ which resembles selaginellin $\mathrm{N}$ in molecular skeleton.

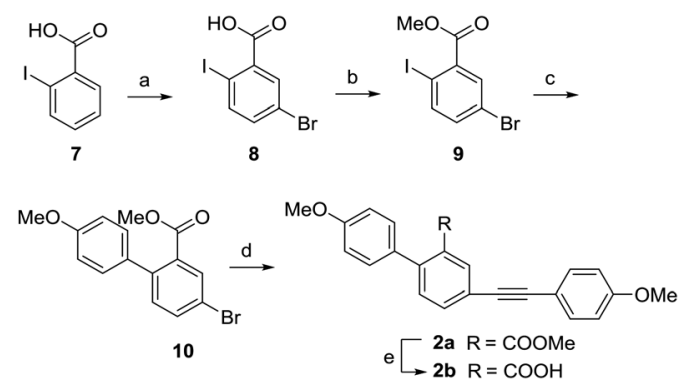

Scheme 4 Synthesis of compounds $2 \mathrm{a}$ and $2 \mathrm{~b}$. Reagents and conditions: (a) $\mathrm{NBS}, \mathrm{H}_{2} \mathrm{SO}_{4}, 60{ }^{\circ} \mathrm{C}, 2 \mathrm{~h}, 86 \%$; (b) $\mathrm{K}_{2} \mathrm{CO}_{3}, \mathrm{CH}_{3}$ l, acetone, $40{ }^{\circ} \mathrm{C}$, 5 h, 100\%; (c) $\mathrm{Na}_{2} \mathrm{CO}_{3}$, 4-methoxyphenylboronic acid, $\mathrm{PdCl}_{2}\left(\mathrm{PPh}_{3}\right)_{2}$, $\mathrm{THF} / \mathrm{H}_{2} \mathrm{O}=1: 1,60^{\circ} \mathrm{C}, 12 \mathrm{~h}, 80 \%$; (d) 4-methoxyphenylacetylene, Cul, $\mathrm{PdCl}_{2}\left(\mathrm{PPh}_{3}\right)_{2}, \mathrm{PPh}_{3}, \mathrm{Et}_{3} \mathrm{~N}, \mathrm{DMF}, 120{ }^{\circ} \mathrm{C}, 12 \mathrm{~h}, 78 \%$; (e) $\mathrm{NaOH}, \mathrm{CH}_{3} \mathrm{OH} /$ $\mathrm{H}_{2} \mathrm{O}=4: 1,100{ }^{\circ} \mathrm{C}, 2 \mathrm{~h}, 99 \%$.

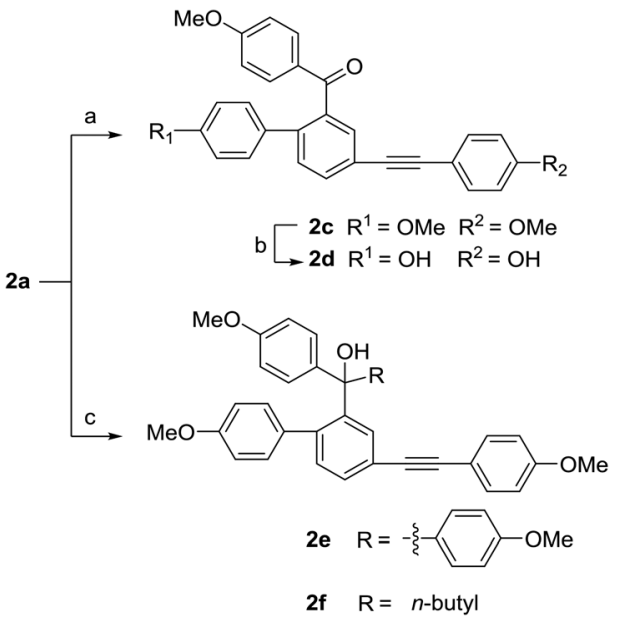

Scheme 5 Synthesis of compounds $2 c-2 f$. Reagents and conditions: (a) 4-methoxyphenylmagnesium bromide, THF, $-83{ }^{\circ} \mathrm{C} \rightarrow$ r.t. $6 \mathrm{~h}$, $36 \%$; (b) $\mathrm{BBr}_{3}, 0{ }^{\circ} \mathrm{C}, 30 \mathrm{~min}, 61 \%$; (c) $n$-BuLi, 1-bromo-4-methoxybenzene, $\mathrm{THF},-83^{\circ} \mathrm{C} \rightarrow 0{ }^{\circ} \mathrm{C}, 4 \mathrm{~h}, 2 \mathrm{e}: 82 \%, 2 \mathrm{f}: 18 \%$.

\subsection{Biological results}

2.2.1. MTT assay for tumor cell growth inhibition. The in vitro cytotoxic activity of the synthesized compounds against MCF-7, HepG2 and L-O2 cells was tested using MTT assay with cisplatin as a positive control. From the experiment data listed in Table 1, the tested compounds with different skeletons exhibited diverse cytotoxic effects. Compounds 1a-1e showed weak cytotoxic effects with the exception of $1 \mathrm{c}\left(\mathrm{IC}_{50}=7.18 \mu \mathrm{M}\right.$ against MCF-7). Among compounds 2a-2j, 2a-2f showed weak cytotoxic effects with the exception of $\mathbf{2 d}$, while $\mathbf{2 g}-\mathbf{2} \mathbf{j}$ showed moderate cytotoxic effects. The cytotoxicity of $2 \mathbf{2 d}$ was more potent than that of 1d, suggesting that the attached position of phenylacetylene greatly influenced their cytotoxicity. Compounds $\mathbf{2 g}$ and $\mathbf{2 h}$ showed much more cytotoxic effects

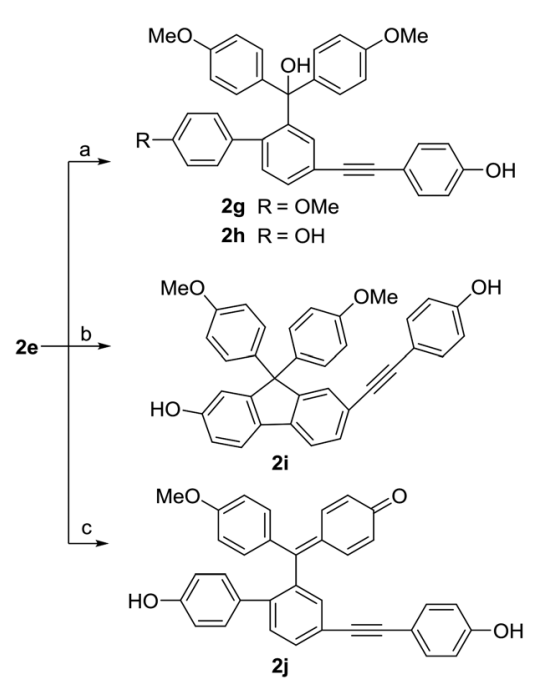

Scheme 6 Synthetic route to compounds $2 \mathrm{~g}-\mathrm{j}$. Reagents and conditions: (a) $\mathrm{BBr}_{3},-83{ }^{\circ} \mathrm{C}, 1 \mathrm{~h}, 2 \mathrm{~g}: 30 \%, 2 \mathrm{~h}: 50 \%$; (b) $\mathrm{BBr}_{3}, 0{ }^{\circ} \mathrm{C}$, 30 min, $27 \%$; (c) $\mathrm{BBr}_{3},-83 \rightarrow 0{ }^{\circ} \mathrm{C}, 4 \mathrm{~h}, 48 \%$. 
Table 1 Anti-proliferative activity of synthesized compounds

\begin{tabular}{|c|c|c|c|}
\hline \multirow[b]{2}{*}{ Compounds } & \multicolumn{3}{|l|}{$\mathrm{IC}_{50}{ }^{a}(\mu \mathrm{M})$} \\
\hline & MCF-7 & HepG2 & $\mathrm{L}-\mathrm{O} 2$ \\
\hline Cisplatin & $7.24 \pm 0.3$ & $9.66 \pm 0.1$ & $3.64 \pm 0.1$ \\
\hline 1a & $>100$ & $>100$ & $>100$ \\
\hline 1b & $>100$ & $>100$ & $>100$ \\
\hline $1 \mathrm{c}$ & $7.18 \pm 1.2$ & $-^{b}$ & $-^{b}$ \\
\hline 1d & $51.16 \pm 0.6$ & $54.75 \pm 1.9$ & $64.00 \pm 1.0$ \\
\hline $1 \mathrm{e}$ & $95.57 \pm 0.4$ & $55.51 \pm 1.9$ & $92.51 \pm 2.0$ \\
\hline $2 a$ & $>100$ & $>100$ & $>100$ \\
\hline $2 \mathbf{b}$ & $>100$ & $>100$ & $>100$ \\
\hline $2 \mathrm{c}$ & $>100$ & $>100$ & $>100$ \\
\hline $2 d$ & $6.49 \pm 0.1$ & $24.99 \pm 0.1$ & $7.83 \pm 1.2$ \\
\hline $2 e$ & $>100$ & $>100$ & $>100$ \\
\hline $2 f$ & $>100$ & $>100$ & $>100$ \\
\hline $2 \mathrm{~g}$ & $12.98 \pm 0.7$ & $15.13 \pm 0.6$ & $16.36 \pm 1.3$ \\
\hline $2 \mathrm{~h}$ & $11.90 \pm 0.5$ & $11.81 \pm 0.8$ & $10.58 \pm 1.1$ \\
\hline $2 \mathbf{i}$ & $9.23 \pm 0.0$ & $8.96 \pm 0.4$ & $10.91 \pm 1.0$ \\
\hline $2 j$ & $12.10 \pm 0.1$ & $11.63 \pm 0.6$ & $11.07 \pm 0.7$ \\
\hline
\end{tabular}

${ }^{a}$ Data are mean values of three independent experiments. Errors represent standard deviation. ${ }^{b}$ The $\mathrm{IC}_{50}$ value was not determined owing to the nonlinear correlation between inhibition rates and concentrations.

than their methylated precursor 2e, suggesting the presence of phenolic hydroxyl favors the antitumor activity of these compounds. Compounds $2 \mathbf{h}, 2 \mathbf{i}$ and $2 \mathbf{j}$ showed similar cytotoxic effects although they possess different scaffolds. Interestingly, compound $2 \mathbf{j}$ with a non-natural skeleton showed more cytotoxic effects than its natural analogs selaginellins, enabling $2 \mathbf{j}$ to be a more promising anti-tumor agent due to its advantage of easier synthesis.

2.2.2. Cell-based reporter assays for hypoxia-inducible factor-1 (HIF-1) inhibition. Almost all solid tumors have a common feature, that is, hypoxia, resulting in overexpression of the HIF pathway in the tumor microenvironment. ${ }^{37}$ Therefore, HIF inhibition has been suggested to be an attractive and promising therapeutic strategy for various solid tumors. To date, the mechanism underlying the anticancer effects of alkynyl phenol derivatives has not been investigated. We here explored the effect of synthesized alkynyl phenol derivatives on HIF pathway by dual luciferase reporter system. The carborane derivative 11, an HIF-1 inhibitor reported by Nakamura, ${ }^{38}$ was used as a reference substance. As the data listed in Table 2, all tested compounds exhibited moderate to strong HIF inhibitory activities except $\mathbf{2 j}$. Compounds $\mathbf{1 a}, \mathbf{2 f}$ and $\mathbf{2 h}$ displayed comparative HIF inhibitory activities and low cytotoxicity compared with compound 11. Different from the rest synthetic derivatives, compound $2 \mathbf{j}$ showed potent anti-proliferative effect, but little HIF inhibitory activity was determined, suggesting a distinct effect resulting from its para-quinone methide moiety.

\section{Experimental section}

\subsection{Chemistry}

All chemicals and solvents were commercially available, at least reagent grade. ${ }^{1} \mathrm{H}$ NMR and ${ }^{13} \mathrm{C}$ NMR spectra were recorded on
Table 2 HIF-1 inhibition in dual luciferase-reporter assay and cell growth inhibition of synthesized compounds

\begin{tabular}{|c|c|c|}
\hline & $11\left(\begin{array}{l}\bullet=\mathrm{BH} \\
\mathrm{O}=\mathrm{C}\end{array}\right)$ & \\
\hline Compounds & HRE $\mathrm{IC}_{50}{ }^{a}(\mu \mathrm{M})$ & $\mathrm{GI}_{50}{ }^{a}(\mu \mathrm{M})$ \\
\hline 11 & $4.46 \pm 0.2$ & $10.80 \pm 1.9$ \\
\hline $1 \mathrm{a}$ & $5.41 \pm 1.1$ & $>100$ \\
\hline $1 b$ & $20.69 \pm 2.5$ & $>100$ \\
\hline $1 \mathrm{c}$ & $2.36 \pm 0.4$ & $3.75 \pm 0.2$ \\
\hline 1d & $9.52 \pm 0.4$ & $44.81 \pm 0.2$ \\
\hline $1 e$ & $13.66 \pm 0.4$ & $86.31 \pm 0.5$ \\
\hline $2 a$ & $18.30 \pm 1.6$ & $>100$ \\
\hline $2 b$ & $15.57 \pm 1.6$ & $>100$ \\
\hline $2 c$ & $39.93 \pm 3.1$ & $>100$ \\
\hline $2 d$ & $4.47 \pm 0.6$ & $3.24 \pm 0.1$ \\
\hline $2 e$ & $20.81 \pm 0.8$ & $>100$ \\
\hline $2 f$ & $1.89 \pm 0.4$ & $>100$ \\
\hline $2 g$ & $8.10 \pm 1.4$ & $15.48 \pm 0.1$ \\
\hline $2 \mathrm{~h}$ & $2.52 \pm 0.4$ & $10.78 \pm 0.3$ \\
\hline $2 \mathbf{i}$ & $5.55 \pm 1.3$ & $7.58 \pm 0.1$ \\
\hline $2 \mathrm{j}$ & $-^{b}$ & $4.47 \pm 0.5$ \\
\hline
\end{tabular}

${ }^{a}$ Data are mean values of three independent experiments. Errors represent standard deviation. ${ }^{b}$ The $\mathrm{IC}_{50}$ value was not determined.

$400 \mathrm{MHz}$ NMR Spectrometer instrument (Bruker Avance II). HRMS data were detected with LTQ Orbitrap XL ETD Mass Spectrometer instrument (Thermo Scientific). The binary solvent system (A/B) of HPLC was as follows: water (A) and $\mathrm{CH}_{3} \mathrm{OH}(\mathrm{B})$; gradient condition: from $60 \% \mathrm{~B}$ to $100 \% \mathrm{~B}$ in $60 \mathrm{~min}$. The absorbance was detected at $254 \mathrm{~nm}$. Reactions were monitored by the thin layer chromatography (TLC) from Qingdao Haiyang Chemical Co. Ltd $(200 \times 200 \mathrm{~mm}, 0.2-0.25 \mathrm{~mm})$. Chromatograms were visualized by $254 \mathrm{~nm}$ UV light.

3.1.1. 2-Bromo-6-iodobenzoic acid (4). Compound 3 (6.03 g, $30.16 \mathrm{mmol}), N$-iodosuccinimide $(8.10 \mathrm{~g}, 36 \mathrm{mmol})$, palladium acetate $(673.5 \mathrm{mg}, 3 \mathrm{mmol})$ and $50 \mathrm{~mL}$ DMF were added to a $100 \mathrm{~mL}$ sealed tube. Then the reaction mixture was stirred at $100{ }^{\circ} \mathrm{C}$ for 12 hours. The mixture was cooled down to room temperature and diluted with ethyl acetate. The solution was washed with $0.5 \mathrm{M} \mathrm{HCl}$ and water. The combined extract was dried by anhydrous sodium sulfate. Ethyl acetate was evaporated under vacuum and the residue was purified by silica gel column chromatography to afford compound 4 (8.84 g, 90\%). White solid; mp $153-155{ }^{\circ} \mathrm{C} ;{ }^{1} \mathrm{H}$ NMR (400 MHz, DMSO$\left.d_{6}\right) \delta 7.09(\mathrm{dd}, J=7.8,7.9 \mathrm{~Hz}, 1 \mathrm{H}), 7.68(\mathrm{~d}, J=7.9 \mathrm{~Hz}, 1 \mathrm{H}), 7.87$ (d, $J=7.8 \mathrm{~Hz}, 1 \mathrm{H})$. HRMS (ESI) $(\mathrm{m} / \mathrm{z}):[\mathrm{M}-\mathrm{H}]^{-}$calcd for $\mathrm{C}_{7} \mathrm{H}_{4} \mathrm{BrIO}_{2}$, 324.8367; found, 324.8369.

3.1.2. Methyl 2-bromo-6-iodobenzoate (5). Compound 4 (7.80 g, $23.93 \mathrm{mmol})$, potassium carbonate (6.66 g, $48.22 \mathrm{mmol})$, $50 \mathrm{~mL}$ acetone and excess methyl iodide were added to a $100 \mathrm{~mL}$ 
round bottom flask. Then the reaction mixture was stirred at $40{ }^{\circ} \mathrm{C}$ for $5 \mathrm{~h}$. Acetone was evaporated under vacuum. The residue was dissolved with ethyl acetate and washed with saturated brine. The combined extract was dried by anhydrous sodium sulfate. Ethyl acetate was evaporated under vacuum to afford compound 5 (8.13 g, 100\%). White solid; mp $87-89{ }^{\circ} \mathrm{C} ;{ }^{1} \mathrm{H}$ NMR (400 MHz, $\left.\mathrm{CDCl}_{3}\right) \delta 7.77(\mathrm{~d}, J=7.9 \mathrm{~Hz}, 1 \mathrm{H}), 7.56(\mathrm{~d}, J=$ $8.1 \mathrm{~Hz}, 1 \mathrm{H}), 6.96(\mathrm{t}, J=8.0 \mathrm{~Hz}, 1 \mathrm{H}), 3.99(\mathrm{~s}, 3 \mathrm{H})$. HRMS (ESI) $(\mathrm{m} /$ $z):[\mathrm{M}+\mathrm{H}]^{+}$calcd for $\mathrm{C}_{8} \mathrm{H}_{6} \mathrm{BrIO}_{2}, 340.8669$; found, 340.8675 .

3.1.3. Methyl 3-bromo-4'-methoxy-[1,1'-biphenyl]-2carboxylate (6). Compound 5 (8.13 g, $23.93 \mathrm{mmol}), p$-methoxyphenylboronic acid (4.36 g, $28.72 \mathrm{mmol}), 50 \mathrm{~mL}$ THF and $50 \mathrm{~mL}$ water were added to a $250 \mathrm{~mL}$ three-necked flask and stirred at room temperature. Bis-triphenylphosphine palladium dichloride (842.3 mg, $1.2 \mathrm{mmol}$ ) was added under nitrogen atmosphere. When the temperature reached $60{ }^{\circ} \mathrm{C}$, sodium carbonate $(5.07 \mathrm{~g}, 47.86 \mathrm{mmol})$ was added. Then the reaction mixture was refluxed for 12 hours. The mixture was cooled to room temperature and diluted with ethyl acetate. The solution was washed with saturated brine. The combined extract was dried by anhydrous sodium sulfate. Ethyl acetate was evaporated under vacuum. The residue was purified by silica gel column chromatography to afford compound 6 (6.28 g, 82\%). White solid; mp 89-91 ${ }^{\circ} \mathrm{C} ;{ }^{1} \mathrm{H}$ NMR $\left(400 \mathrm{MHz}\right.$, acetone- $\left.d_{6}\right) \delta 7.64$ (dd, $J=7.0,1.9 \mathrm{~Hz}, 1 \mathrm{H}), 7.47-7.42(\mathrm{t}, 1 \mathrm{H}), 7.41(\mathrm{~d}, J=6.0 \mathrm{~Hz}$, $1 \mathrm{H}), 7.33(\mathrm{~d}, J=8.7 \mathrm{~Hz}, 2 \mathrm{H}), 7.00(\mathrm{~d}, J=8.7 \mathrm{~Hz}, 2 \mathrm{H}), 3.83(\mathrm{~s}, 3 \mathrm{H})$, 3.69 (s, 3H). HRMS (ESI) $(\mathrm{m} / \mathrm{z})$ : $[\mathrm{M}+\mathrm{H}]^{+}$calcd for $\mathrm{C}_{15} \mathrm{H}_{13} \mathrm{BrO}_{3}$, 321.0121; found, 321.0126.

3.1.4. Methyl $\quad 4^{\prime}$-methoxy-3-((4-methoxyphenyl)ethynyl)[1,1'-biphenyl]-2-carboxylate (1a). Compound 6 (5.08 g, 15.88 $\mathrm{mmol})$, triphenylphosphine (416.5 $\mathrm{mg}, 1.59 \mathrm{mmol})$, cuprous iodide (151.2 mg, $0.79 \mathrm{mmol}$ ) and $30 \mathrm{~mL}$ DMF were added to a $250 \mathrm{~mL}$ three-necked flask and stirred at room temperature. Bis-triphenylphosphine palladium dichloride $(557.3 \mathrm{mg}, 0.79$ $\mathrm{mmol})$ and 4-ethynylanisole $(8.24 \mathrm{~mL}, 63.52 \mathrm{mmol})$ were added under nitrogen atmosphere. Then $30 \mathrm{~mL}$ triethylamine was added and refluxed at $120{ }^{\circ} \mathrm{C}$ for 12 hours. The reaction mixture was cooled to room temperature and diluted with ethyl acetate. The solution was washed with saturated ammonium chloride solution. The combined extract was dried by anhydrous sodium sulfate. Ethyl acetate was evaporated under vacuum. The residue was purified by silica gel column chromatography to afford compound 1a $(3.0 \mathrm{~g}, 48 \%)$. White solid; mp $98-99^{\circ} \mathrm{C}$; the purity of the compound was detected by analytical HPLC to be over 95\%. ${ }^{1} \mathrm{H}$ NMR (400 MHz, $\left.\mathrm{CDCl}_{3}\right) \delta 7.51$ (dd, $J=7.7,1.1 \mathrm{~Hz}$, $1 \mathrm{H}), 7.44(\mathrm{~d}, J=8.8 \mathrm{~Hz}, 2 \mathrm{H}), 7.40(\mathrm{~d}, J=7.7 \mathrm{~Hz}, 1 \mathrm{H}), 7.33$ (d, $J=$ $8.7 \mathrm{~Hz}, 2 \mathrm{H}), 7.32-7.30(\mathrm{~m}, 1 \mathrm{H}), 6.94(\mathrm{~d}, J=8.7 \mathrm{~Hz}, 2 \mathrm{H}), 6.87$ (d, $J$ $=8.8 \mathrm{~Hz}, 2 \mathrm{H}), 3.84(\mathrm{~s}, 3 \mathrm{H}), 3.83(\mathrm{~s}, 3 \mathrm{H}), 3.74(\mathrm{~s}, 3 \mathrm{H}) ;{ }^{13} \mathrm{C} \mathrm{NMR}$ (101 MHz, DMSO- $d_{6}$ ) $\delta 168.57,159.88,159.11,138.87,135.18$, 133.03 , 131.29, 129.99, 129.58, 129.17, 120.65, 114.56, 114.16, 113.66, 92.89, 85.36, 55.34, 55.18, 52.21. HRMS (ESI) $(\mathrm{m} / \mathrm{z}):[\mathrm{M}+$ $\mathrm{H}]^{+}$calcd for $\mathrm{C}_{24} \mathrm{H}_{20} \mathrm{O}_{4}, 373.1434$; found, 373.1439.

3.1.5. $\quad 4^{\prime}$-Methoxy-3-((4-methoxyphenyl)ethynyl)-[1,1'-biphe nyl]-2-carboxylic acid (1b). Compound 1a (722.0 mg, 1.94 $\mathrm{mmol}$ ), $50 \mathrm{~mL}$ methanol and $10 \mathrm{~mL} \mathrm{60 \%} \mathrm{sodium} \mathrm{hydroxide}$ solution were added to a $100 \mathrm{~mL}$ round bottom flask. Then the reaction mixture was refluxed at $80^{\circ} \mathrm{C}$ for 8 hours. The mixture was cooled to room temperature. The solvent was evaporated under vacuum. The residue was diluted with ethyl acetate and washed with dilute hydrochloric acid and saturated brine. The combined extract was dried by anhydrous sodium sulfate. Ethyl acetate was evaporated under vacuum. The residue was purified by silica gel chromatography to afford compound $\mathbf{1 b}(538.0 \mathrm{mg}$, $77 \%)$. White solid; mp $145-147^{\circ} \mathrm{C}$; the purity of the compound was detected by analytical HPLC to be over 95\%. ${ }^{1} \mathrm{H}$ NMR (400 MHz, acetone- $\left.d_{6}\right) \delta 7.55(\mathrm{dd}, J=7.7,1.3 \mathrm{~Hz}, 1 \mathrm{H}), 7.52-7.45(\mathrm{~m}$, $3 \mathrm{H}), 7.45-7.41(\mathrm{~m}, 2 \mathrm{H}), 7.38(\mathrm{dd}, J=7.6,1.3 \mathrm{~Hz}, 1 \mathrm{H}), 7.01-6.94$ $(\mathrm{m}, 4 \mathrm{H}), 3.83(\mathrm{~s}, 6 \mathrm{H}) ;{ }^{13} \mathrm{C}$ NMR $\left(101 \mathrm{MHz}\right.$, acetone- $\left.d_{6}\right) \delta 169.79$, $161.07,160.45$, 140.02, 137.66, 133.87, 133.11, 130.90, 130.45, $130.36,129.97,121.94,115.67,115.05,114.66$, 93.48, 86.65, 55.71, 55.56. HRMS (ESI) $(\mathrm{m} / z):[\mathrm{M}-\mathrm{H}]^{-}$calcd for $\mathrm{C}_{23} \mathrm{H}_{18} \mathrm{O}_{4}$, 357.1132; found, 357.1138 .

3.1.6. (4'-Methoxy-3-((4-methoxyphenyl)ethynyl)-[1,1'-biph enyl]-2-yl)(4-methoxyphenyl)methanone (1c). Compound $1 \mathrm{~b}$ (365.4 $\mathrm{mg}, 1.02 \mathrm{mmol}$ ) was dissolved in $3 \mathrm{~mL}$ dichloromethane. Then the reaction mixture was stirred in an ice water bath and $0.2 \mathrm{~mL}$ thionyl chloride was added, followed by a drop of DMF. After being stirred for 2 hours, the solvent was evaporated under vacuum. The residue was dissolved in $2 \mathrm{~mL}$ THF under nitrogen atmosphere for use. Parabromoanisole $(308 \mu \mathrm{L}, 2.4 \mathrm{mmol})$ and $3 \mathrm{~mL}$ anhydrous THF were added to a $50 \mathrm{~mL}$ dry round bottom flask under nitrogen atmosphere. Then the reaction mixture was stirred at $-83{ }^{\circ} \mathrm{C}$ and $1.7 \mathrm{~mL} n \mathrm{BuLi}$ in $n$-hexane solution (1.6 $\mathrm{M} \mathrm{L}^{-1}$ ) was added. After being stirred for $30 \mathrm{~min}$, the prepared acid chloride was added to the reaction mixture and stirred for $2 \mathrm{~h}$. The reaction mixture was quenched by adding saturated ammonium chloride solution. The reaction mixture was diluted with ethyl acetate and washed with saturated brine. The combined extract was dried by anhydrous sodium sulfate. Ethyl acetate was evaporated under vacuum. The residue was purified by silica gel chromatography to afford compound 1c $1170.3 \mathrm{mg}$, $38 \%$ ). White solid; mp $48-49{ }^{\circ} \mathrm{C}$; the purity of the compound was detected by analytical HPLC to be over $95 \% .{ }^{1} \mathrm{H}$ NMR (400 MHz, DMSO- $\left.d_{6}\right) \delta 7.65(\mathrm{~d}, J=8.9 \mathrm{~Hz}, 2 \mathrm{H}), 7.61-7.56(\mathrm{~m}, 2 \mathrm{H})$, $7.46(\mathrm{dd}, J=6.1,2.9 \mathrm{~Hz}, 1 \mathrm{H}), 7.20$ (d, $J=8.7 \mathrm{~Hz}, 2 \mathrm{H}), 7.03-6.97$ (m, 4H), 6.89-6.83 (m, 4H), $3.80(\mathrm{~s}, 3 \mathrm{H}), 3.74(\mathrm{~s}, 3 \mathrm{H}), 3.70(\mathrm{~s}, 3 \mathrm{H})$; ${ }^{13} \mathrm{C}$ NMR $\left(101 \mathrm{MHz}, \mathrm{DMSO}-d_{6}\right) \delta 195.25,163.39,159.65,158.73$, 141.09, 139.22, 132.50, 131.49, 131.41, 129.99, 129.92, 129.80, $129.33,120.45,114.30,114.12$, 113.78, 113.59, 93.82, 86.17, 55.55, 55.25, 55.02. HRMS (ESI) $(\mathrm{m} / \mathrm{z}):[\mathrm{M}+\mathrm{H}]^{+}$calcd for $\mathrm{C}_{30} \mathrm{H}_{24} \mathrm{O}_{4}, 449.1747$; found, 449.1744 .

3.1.7. (4'-Hydroxy-3-((4-hydroxyphenyl)ethynyl)-[1,1'-biphe nyl]-2-yl)(4-methoxyphenyl)methanone (1d). Compound 1c (150.8 $\mathrm{mg}, 0.34 \mathrm{mmol}$ ) was dissolved in $2 \mathrm{~mL}$ dry dichloromethane in a $10 \mathrm{~mL}$ chicken heart flask. Then the reaction mixture was stirred in an ice water bath and boron tribromide $(320 \mu \mathrm{L}, 3.38 \mathrm{mmol})$ was added. After being stirred for $30 \mathrm{~min}$, $3 \mathrm{~mL}$ diethyl ether was added. The reaction mixture was stirred for $20 \mathrm{~min}$ and saturated sodium bicarbonate solution was slowly added. Then the reaction mixture was diluted with ethyl acetate and washed with saturated brine. The combined extract was dried by anhydrous sodium sulfate. Ethyl acetate was evaporated under vacuum. The residue was purified by silica gel chromatography to afford compound 1d (24.5 mg, 17\%). White 
solid; mp 91-93 ${ }^{\circ} \mathrm{C}$; the purity of the compound was detected by analytical HPLC to be over 95\%. ${ }^{1} \mathrm{H}$ NMR ( $400 \mathrm{MHz}$, acetone- $d_{6}$ ) $\delta 8.73(\mathrm{~s}, 1 \mathrm{H}), 8.39(\mathrm{~s}, 1 \mathrm{H}), 7.70(\mathrm{~d}, J=8.8 \mathrm{~Hz}, 2 \mathrm{H}), 7.57-7.51(\mathrm{~m}$, 2H), $7.42(\mathrm{dd}, J=5.9,3.0 \mathrm{~Hz}, 1 \mathrm{H}), 7.18$ (d, $J=8.5 \mathrm{~Hz}, 2 \mathrm{H}), 7.01$ $(\mathrm{d}, J=8.5 \mathrm{~Hz}, 2 \mathrm{H}), 6.93(\mathrm{~d}, J=8.8 \mathrm{~Hz}, 2 \mathrm{H}), 6.75(\mathrm{~d}, J=8.5 \mathrm{~Hz}$, $2 \mathrm{H}), 6.73$ (d, $J=8.5 \mathrm{~Hz}, 2 \mathrm{H}), 3.82(\mathrm{~s}, 3 \mathrm{H}) ;{ }^{13} \mathrm{C}$ NMR $(101 \mathrm{MHz}$, acetone- $\left.d_{6}\right) \delta 195.31,163.70,158.01,157.02,141.74,140.12$, 132.86, 131.63, 131.06, 130.77, 130.21, 129.81, 129.55, 128.90, 121.49, 115.47, 115.06, 113.75, 113.53, 94.09, 85.79, 55.02. HRMS (ESI) $(m / z):[\mathrm{M}-\mathrm{H}]^{-}$calcd for $\mathrm{C}_{28} \mathrm{H}_{20} \mathrm{O}_{4}, 449.1289$; found, 419.1293 .

3.1.8. 3,8-Bis(4-hydroxyphenyl)-1H-isochromen-1-one (1e). Compound 1a (186.5 mg, $0.50 \mathrm{mmol})$ was dissolved in $2 \mathrm{~mL}$ dry dichloromethane in a $10 \mathrm{~mL}$ chicken heart flask. Then the reaction mixture was stirred in an ice water bath and boron tribromide ( $470 \mu \mathrm{L}, 4.97 \mathrm{mmol}$ ) was added. After being stirred for 2 hours, $3 \mathrm{~mL}$ diethyl ether was added. The reaction mixture was stirred for $20 \mathrm{~min}$ and saturated sodium bicarbonate solution was slowly added. The reaction mixture was diluted with ethyl acetate and washed with saturated brine. The combined extract was dried by anhydrous sodium sulfate. Ethyl acetate was evaporated under vacuum. The residue was purified by silica gel chromatography to afford compound 1e $(54.9 \mathrm{mg}$, $33 \%$ ). Light yellow solid; mp $297-299{ }^{\circ} \mathrm{C}$; the purity of the compound was detected by analytical HPLC to be over $95 \% .{ }^{1} \mathrm{H}$ NMR (400 MHz, acetone- $\left.d_{6}\right) \delta 8.87(\mathrm{~s}, 1 \mathrm{H}), 8.36(\mathrm{~s}, 1 \mathrm{H}), 7.80(\mathrm{~d}, J$ $=8.7 \mathrm{~Hz}, 2 \mathrm{H}), 7.74(\mathrm{t}, J=7.7 \mathrm{~Hz}, 1 \mathrm{H}), 7.58(\mathrm{~d}, J=7.8 \mathrm{~Hz}, 1 \mathrm{H})$, $7.29(\mathrm{~d}, J=7.5 \mathrm{~Hz}, 1 \mathrm{H}), 7.21(\mathrm{~d}, J=8.4 \mathrm{~Hz}, 2 \mathrm{H}), 7.16(\mathrm{~s}, 1 \mathrm{H}), 6.98$ $(\mathrm{d}, J=8.7 \mathrm{~Hz}, 2 \mathrm{H}), 6.87$ (d, $J=8.4 \mathrm{~Hz}, 2 \mathrm{H}) ;{ }^{13} \mathrm{C} \mathrm{NMR}(101 \mathrm{MHz}$, acetone- $\left.d_{6}\right) \delta 160.51,160.13,157.68,154.57,146.79,140.77$, 134.62, 133.82, 131.82, 130.85, 127.65, 126.18, 124.49, 117.92, 116.66, 115.25, 100.76. HRMS (ESI) $(\mathrm{m} / \mathrm{z}):[\mathrm{M}-\mathrm{H}]^{-}$calcd for $\mathrm{C}_{21} \mathrm{H}_{14} \mathrm{O}_{4}, 329.0819$; found, 329.0829 .

3.1.9. 5-Bromo-2-iodobenzoic acid (8). Compound 7 ( $8.44 \mathrm{~g}, 34.03 \mathrm{mmol}$ ) and $60 \mathrm{~mL} \mathrm{H}_{2} \mathrm{SO}_{4}$ were added to a $250 \mathrm{~mL}$ round bottom flask. NBS $(4.82 \mathrm{~g}, 38.06 \mathrm{mmol})$ was then added at $60{ }^{\circ} \mathrm{C}$ and the mixture was stirred for 2 hours. Then the reaction mixture was cooled to room temperature and dropped into ice water. The mixture was diluted with ethyl acetate and washed with saturated brine. The combined extract was dried by anhydrous sodium sulfate. Ethyl acetate was evaporated under vacuum. The residue was purified by silica gel chromatography to afford compound 8 (9.54 g, 86\%). White solid; mp 159$161{ }^{\circ} \mathrm{C} ;{ }^{1} \mathrm{H}$ NMR $\left(400 \mathrm{MHz}, \mathrm{CDCl}_{3}\right) \delta 8.14(\mathrm{~d}, J=2.4 \mathrm{~Hz}, 1 \mathrm{H}), 7.90$ $(\mathrm{d}, J=8.4 \mathrm{~Hz}, 1 \mathrm{H}), 7.33(\mathrm{dd}, J=8.4,2.4 \mathrm{~Hz}, 1 \mathrm{H}) . \operatorname{HRMS}(\mathrm{ESI})(\mathrm{m} /$ $z):[\mathrm{M}-\mathrm{H}]^{-}$calcd for $\mathrm{C}_{7} \mathrm{H}_{4} \mathrm{BrIO}_{2}, 324.8367$; found, 324.8369 .

3.1.10. Methyl 5-bromo-2-iodobenzoate (9). Compound 8 (9.54 g, $29.4 \mathrm{mmol})$, potassium carbonate ( $8.13 \mathrm{~g}, 58.8 \mathrm{mmol})$, $50 \mathrm{~mL}$ acetone and excess methyl iodide were successively added to a $100 \mathrm{~mL}$ round bottom flask. Then the reaction mixture was stirred at $40{ }^{\circ} \mathrm{C}$ for $5 \mathrm{~h}$. Acetone was evaporated under vacuum. The residue was diluted with ethyl acetate and washed with saturated brine. The combined extract was dried by anhydrous sodium sulfate. Ethyl acetate was evaporated under vacuum to afford compound 9 (9.99 g, 100\%). White solid; mp 48-49 ${ }^{\circ} \mathrm{C} ;{ }^{1} \mathrm{H}$ NMR (400 MHz, acetone- $\left.d_{6}\right) \delta 7.98(\mathrm{~d}, J=8.4 \mathrm{~Hz}$, $1 \mathrm{H}), 7.91$ (d, $J=2.4 \mathrm{~Hz}, 1 \mathrm{H}), 7.48$ (dd, $J=8.4,2.4 \mathrm{~Hz}, 1 \mathrm{H}), 3.92$ (s, 3H). HRMS (ESI) $(m / z):[\mathrm{M}+\mathrm{H}]^{+}$calcd for $\mathrm{C}_{8} \mathrm{H}_{6} \mathrm{BrIO}_{2}$, 340.8669; found, 340.8675 .

3.1.11. Methyl 4-bromo-4'-methoxy-[1,1'-biphenyl]-2carboxylate (10). Compound 9 (9.99 g, $29.4 \mathrm{mmol}), p$-methoxyphenylboronic acid $(5.36 \mathrm{~g}, 35.28 \mathrm{mmol}), 50 \mathrm{~mL}$ THF and $50 \mathrm{~mL}$ water were successively added to a $250 \mathrm{~mL}$ three-necked flask and stirred at room temperature. Bis-triphenylphosphine palladium dichloride (1.03 g, $1.47 \mathrm{mmol})$ was then added under nitrogen atmosphere. When the temperature reached $60{ }^{\circ} \mathrm{C}$, sodium carbonate $(6.23 \mathrm{~g}, 58.8 \mathrm{mmol})$ was added. Then the reaction mixture was refluxed for 12 hours. The mixture was cooled to room temperature and diluted with ethyl acetate. The solution was washed with saturated brine. The combined extract was dried by anhydrous sodium sulfate. Ethyl acetate was evaporated under vacuum. The residue was purified by silica gel chromatography to afford compound 10 (7.53 g, 80\%). White solid; mp $76-77^{\circ} \mathrm{C} ;{ }^{1} \mathrm{H}$ NMR $\left(400 \mathrm{MHz}\right.$, acetone- $\left.d_{6}\right) \delta 7.86$ (d, $J=2.2 \mathrm{~Hz}, 1 \mathrm{H}), 7.75(\mathrm{dd}, J=8.3,2.2 \mathrm{~Hz}, 1 \mathrm{H}), 7.38$ (d, $J=$ $8.3 \mathrm{~Hz}, 1 \mathrm{H}), 7.28-7.21(\mathrm{~m}, 2 \mathrm{H}), 7.02-6.95(\mathrm{~m}, 2 \mathrm{H}), 3.84(\mathrm{~s}, 3 \mathrm{H})$, $3.66(\mathrm{~s}, 3 \mathrm{H})$. HRMS (ESI) $(\mathrm{m} / \mathrm{z}):[\mathrm{M}+\mathrm{H}]^{+}$calcd for $\mathrm{C}_{15} \mathrm{H}_{13} \mathrm{BrO}_{3}$, 321.0121; found, 321.0126.

3.1.12. Methyl $\quad 4^{\prime}$-methoxy-4-((4-methoxyphenyl)ethynyl)[1,1'-biphenyl]-2-carboxylate (2a). Compound 10 (7.53 g, 23.535 $\mathrm{mmol})$, triphenylphosphine $(617.3 \mathrm{mg}, 2.35 \mathrm{mmol})$, cuprous iodide (224.1 mg, $1.18 \mathrm{mmol}$ ) and $40 \mathrm{~mL}$ DMF were added to a $250 \mathrm{~mL}$ three-necked flask and stirred at room temperature. Bis-triphenylphosphine palladium dichloride $(826.0 \mathrm{mg}, 1.18$ $\mathrm{mmol}$ ) and 4-ethynylanisole $(9.5 \mathrm{~mL}, 73.25 \mathrm{mmol})$ were added under nitrogen atmosphere. Then $40 \mathrm{~mL}$ triethylamine was added and refluxed at $120{ }^{\circ} \mathrm{C}$ for 8 hours. The reaction mixture was cooled to room temperature and diluted with ethyl acetate. The solution was washed with saturated ammonium chloride solution. The combined extract was dried by anhydrous sodium sulfate. Ethyl acetate was evaporated under vacuum. The residue was purified by silica gel chromatography to afford compound 2a (6.84 g, 78\%). White solid; mp $138-139{ }^{\circ} \mathrm{C}$; the purity of the compound was detected by analytical HPLC to be over 95\%. ${ }^{1} \mathrm{H}$ NMR (400 MHz, acetone- $\left.d_{6}\right) \delta 7.83(\mathrm{~d}, J=1.8 \mathrm{~Hz}$, $1 \mathrm{H}), 7.69(\mathrm{dd}, J=8.0,1.8 \mathrm{~Hz}, 1 \mathrm{H}), 7.57-7.50(\mathrm{~m}, 2 \mathrm{H}), 7.46(\mathrm{~d}, J=$ $8.0 \mathrm{~Hz}, 1 \mathrm{H}), 7.32-7.26(\mathrm{~m}, 2 \mathrm{H}), 7.03-6.96(\mathrm{~m}, 4 \mathrm{H}), 3.86(\mathrm{~s}, 3 \mathrm{H})$, $3.85(\mathrm{~s}, 3 \mathrm{H}), 3.67(\mathrm{~s}, 3 \mathrm{H}) ;{ }^{13} \mathrm{C}$ NMR (101 MHz, DMSO- $\left.d_{6}\right)$ $\delta 168.05,159.75,158.97,140.26,133.48,133.09,131.73,131.70$, $131.26,130.81,129.31,121.33,114.45,113.86,90.81,86.79$, 55.30, 55.14, 52.14. HRMS (ESI) $(\mathrm{m} / \mathrm{z}):[\mathrm{M}+\mathrm{H}]^{+}$calcd for $\mathrm{C}_{24} \mathrm{H}_{20} \mathrm{O}_{4}, 373.1434$; found, 373.1442.

3.1.13. $\quad 4^{\prime}$-Methoxy-4-((4-methoxyphenyl)ethynyl)-[1,1'-biph enyl]-2-carboxylic acid (2b). Compound 2a (372.1 $\mathrm{mg}, 1 \mathrm{mmol})$, sodium hydroxide $(1.0 \mathrm{~g}), 20 \mathrm{~mL}$ methanol and $5 \mathrm{~mL}$ water were added to a $100 \mathrm{~mL}$ round bottom flask. Then the reaction mixture was refluxed at $100{ }^{\circ} \mathrm{C}$ for 2 hours. The mixture was cooled to room temperature. The solvent was evaporated under vacuum. The residue was diluted with ethyl acetate and washed with dilute hydrochloric acid and saturated brine. The combined extract was dried by anhydrous sodium sulfate. Ethyl acetate was evaporated under vacuum. The residue was purified by silica gel chromatography to afford compound $2 \mathbf{b}(354.5 \mathrm{mg}$, 99\%). White solid; mp $191-193{ }^{\circ} \mathrm{C}$; the purity of the compound 
was detected by analytical HPLC to be over 95\%. ${ }^{1} \mathrm{H}$ NMR (400 MHz, DMSO- $\left.d_{6}\right) \delta 12.98(\mathrm{~s}, 1 \mathrm{H}), 7.79(\mathrm{~d}, J=1.7 \mathrm{~Hz}, 1 \mathrm{H}), 7.66$ (dd, $J=8.0,1.8 \mathrm{~Hz}, 1 \mathrm{H}), 7.56-7.51(\mathrm{~m}, 2 \mathrm{H}), 7.41(\mathrm{~d}, J=8.0 \mathrm{~Hz}, 1 \mathrm{H})$, 7.33-7.27 (m, 2H), 7.03-6.96 (m, 4H), 3.81 (s, 3H), 3.80 (s, 3H); ${ }^{13} \mathrm{C}$ NMR $\left(101 \mathrm{MHz}, \mathrm{DMSO}-d_{6}\right) \delta 169.65,160.20,159.38,140.51$, 133.55, 133.38, 133.31, 132.63, 131.97, 131.24, 129.92, 121.66, 114.92, 114.44, 114.21, 91.06, 87.49, 55.77, 55.61. HRMS (ESI) $(\mathrm{m} / \mathrm{z}):[\mathrm{M}-\mathrm{H}]^{-}$calcd for $\mathrm{C}_{23} \mathrm{H}_{18} \mathrm{O}_{4}, 357.1132$; found, 357.1139.

3.1.14. (4'-Methoxy-4-((4-methoxyphenyl)ethynyl)-[1,1' biphenyl]-2-yl)(4-methoxyphenyl)methanone (2c). Compound $2 \mathrm{a}(744.3 \mathrm{mg}, 2 \mathrm{mmol})$ and $5 \mathrm{~mL}$ of anhydrous THF were added to a $50 \mathrm{~mL}$ dry round bottom flask under nitrogen atmosphere. Then the reaction mixture was stirred at $-83{ }^{\circ} \mathrm{C}$ and $2.5 \mathrm{~mL}$ of $p$ methoxyphenylmagnesium bromide $\left(1.0 \mathrm{M} \mathrm{L}^{-1}\right.$ in THF) was added. The temperature was naturally raised to room temperature. After being stirred for 6 hours, the reaction mixture was quenched by adding saturated ammonium chloride solution. The reaction mixture was diluted with ethyl acetate and washed with saturated brine. The combined extract was dried by anhydrous sodium sulfate. Ethyl acetate was evaporated under vacuum. The residue was purified by silica gel chromatography to afford compound $2 \mathrm{c}$ (319.2 $\mathrm{mg}, 36 \%)$. White solid; mp 153$155{ }^{\circ} \mathrm{C}$; the purity of the compound was detected by analytical HPLC to be over $95 \% .{ }^{1} \mathrm{H}$ NMR $\left(400 \mathrm{MHz}\right.$, DMSO- $\left.d_{6}\right) \delta 7.72(\mathrm{dd}, J$ $=8.0,1.8 \mathrm{~Hz}, 1 \mathrm{H}), 7.64-7.59(\mathrm{~m}, 2 \mathrm{H}), 7.52(\mathrm{~m}, J=4.8,3.9 \mathrm{~Hz}$, $4 \mathrm{H}), 7.23-7.16(\mathrm{~m}, 2 \mathrm{H}), 7.01-6.97(\mathrm{~m}, 2 \mathrm{H}), 6.97-6.93(\mathrm{~m}, 2 \mathrm{H})$, 6.88-6.82 (m, 2H); ${ }^{13} \mathrm{C}$ NMR (101 MHz, DMSO- $\left.d_{6}\right) \delta$ 195.37, 163.36, 159.70, 158.83, 139.10, 139.06, 133.05, 132.40, 131.97, 131.31, 130.38, 130.28, 129.68, 129.32, 121.13, 114.43, 113.99, 113.95, 90.74, 87.15, 55.56, 55.29, 55.06. HRMS (ESI) $(\mathrm{m} / \mathrm{z}):[\mathrm{M}+$ $\mathrm{H}]^{+}$calcd for $\mathrm{C}_{30} \mathrm{H}_{24} \mathrm{O}_{4}, 449.1747$; found, 449.1741 .

3.1.15. (4'-Hydroxy-4-((4-hydroxyphenyl)ethynyl)-[1,1'biphenyl]-2-yl)(4-methoxyphenyl)methanone (2d). Compound 2c (319.2 $\mathrm{mg}, 0.71 \mathrm{mmol}$ ) was dissolved in $5 \mathrm{~mL}$ dry dichloromethane added in a $50 \mathrm{~mL}$ round bottom flask. Then the reaction mixture was stirred in an ice water bath and boron tribromide ( $340 \mu \mathrm{L}, 3.6 \mathrm{mmol})$ was added. After being stirred for $30 \mathrm{~min}, 10 \mathrm{~mL}$ diethyl ether was added. The reaction mixture was stirred for $20 \mathrm{~min}$ and saturated sodium bicarbonate solution was slowly added. Then the reaction mixture was diluted with ethyl acetate and washed with saturated brine. The combined extract was dried by anhydrous sodium sulfate. Ethyl acetate was evaporated under vacuum. The residue was purified by silica gel chromatography to afford compound $2 d(180.7 \mathrm{mg}$, $61 \%)$. White solid; mp $229-231{ }^{\circ} \mathrm{C}$; the purity of the compound was detected by analytical HPLC to be over 95\%. ${ }^{1} \mathrm{H}$ NMR (400 MHz, DMSO- $\left.d_{6}\right) \delta 9.97(\mathrm{~s}, 1 \mathrm{H}), 9.54(\mathrm{~s}, 1 \mathrm{H}), 7.68(\mathrm{dd}, J=8.0$, $1.7 \mathrm{~Hz}, 1 \mathrm{H}), 7.58(\mathrm{~d}, J=8.8 \mathrm{~Hz}, 2 \mathrm{H}), 7.49(\mathrm{~d}, J=8.1 \mathrm{~Hz}, 1 \mathrm{H}), 7.46$ $(\mathrm{d}, J=1.6 \mathrm{~Hz}, 1 \mathrm{H}), 7.39(\mathrm{~d}, J=8.6 \mathrm{~Hz}, 2 \mathrm{H}), 7.08(\mathrm{~d}, J=8.5 \mathrm{~Hz}$, $2 \mathrm{H}), 6.93(\mathrm{~d}, J=8.9 \mathrm{~Hz}, 2 \mathrm{H}), 6.80(\mathrm{~d}, J=8.6 \mathrm{~Hz}, 2 \mathrm{H}), 6.65(\mathrm{~d}, J=$ $8.5 \mathrm{~Hz}, 2 \mathrm{H}), 3.79(\mathrm{~s}, 3 \mathrm{H}) ;{ }^{13} \mathrm{C}$ NMR $\left(101 \mathrm{MHz}, \mathrm{DMSO}-d_{6}\right) \delta 195.60$, 163.25, 158.23, 157.08, 139.30, 138.94, 133.13, 132.31, 131.88, 130.34, 130.03, 129.75, 129.70, 129.35, 121.12, 115.77, 115.34, 113.89, 112.24, 91.16, 86.60, 55.51. HRMS (ESI) $(\mathrm{m} / \mathrm{z}):[\mathrm{M}+\mathrm{H}]^{+}$ calcd for $\mathrm{C}_{28} \mathrm{H}_{20} \mathrm{O}_{4}, 421.1434$; found, 421.1432.

3.1.16. (4'-Methoxy-4-((4-methoxyphenyl)ethynyl)-[1,1' biphenyl]-2-yl)bis(4-methoxyphenyl)methanol (2e); 1-(4'- methoxy-4-((4-methoxyphenyl)ethynyl)-[1,1'-biphenyl]-2-yl)-1-(4methoxyphenyl)pentan-1-ol (2f). Parabromoanisole (2.03 g, $10.84 \mathrm{mmol}$ ) and $5 \mathrm{~mL}$ anhydrous THF were added to a $100 \mathrm{~mL}$ dry round bottom flask under nitrogen atmosphere. Then the reaction mixture was stirred at $-83{ }^{\circ} \mathrm{C}$ and $7.45 \mathrm{~mL} n$-BuLi in $n$ hexane solution $\left(1.6 \mathrm{M} \mathrm{L}^{-1}\right.$ ) was added. After being stirred for 1 hour, $15 \mathrm{~mL}$ solution of compound $2 \mathrm{a}(2.02 \mathrm{~g}, 5.42 \mathrm{mmol})$ in THF was added to the reaction mixture. The temperature was naturally raised to $0{ }^{\circ} \mathrm{C}$. The reaction mixture was stirred for 4 hours and quenched by adding saturated ammonium chloride solution. The reaction mixture was diluted with ethyl acetate and washed with saturated brine. The combined extract was dried by anhydrous sodium sulfate. Ethyl acetate was evaporated under vacuum. The residue was purified by silica gel chromatography to afford compound $2 \mathrm{e}(2.47 \mathrm{~g}, 82 \%)$ and compound $2 f(493.9 \mathrm{mg}, 18 \%)$. The purity of the two compounds was detected by analytical HPLC to be over $95 \%$. Compound 2e: pink solid; mp $179-181{ }^{\circ} \mathrm{C} ;{ }^{1} \mathrm{H}$ NMR $(400 \mathrm{MHz}$, DMSO- $\left.d_{6}\right) \delta 8.09(\mathrm{~d}, J=1.5 \mathrm{~Hz}, 1 \mathrm{H}), 7.51(\mathrm{~d}, J=8.6 \mathrm{~Hz}, 2 \mathrm{H}), 7.34$ (dd, $J=7.7,1.4 \mathrm{~Hz}, 1 \mathrm{H}), 6.98(\mathrm{~d}, J=8.6 \mathrm{~Hz}, 2 \mathrm{H}), 6.85-6.89(\mathrm{~m}$, $3 \mathrm{H}), 6.68(\mathrm{~d}, J=8.7 \mathrm{~Hz}, 2 \mathrm{H}), 6.61(\mathrm{~d}, J=8.4 \mathrm{~Hz}, 2 \mathrm{H}), 6.44(\mathrm{~d}, J=$ $8.2 \mathrm{~Hz}, 2 \mathrm{H}), 4.79(\mathrm{~s}, 1 \mathrm{H}), 3.81(\mathrm{~s}, 3 \mathrm{H}), 3.72(\mathrm{~s}, 6 \mathrm{H}), 1.99-1.84(\mathrm{~m}$, $2 \mathrm{H}), 1.30-1.11(\mathrm{~m}, 3 \mathrm{H}), 1.03-0.88(\mathrm{~m}, 1 \mathrm{H}), 0.79(\mathrm{t}, J=7.2 \mathrm{~Hz}$, $3 \mathrm{H}) ;{ }^{13} \mathrm{C}$ NMR (101 MHz, DMSO- $\left.d_{6}\right) \delta 159.51,157.76,157.67$, $145.84,140.71,140.39,134.13,132.95,132.33,129.64,128.64$, $127.71,120.74,114.42,114.37,112.71,112.17,89.16,88.54$, $75.70,55.28,55.05,54.98,38.47,25.73,22.60,14.11$. ESI MS $(\mathrm{m} /$ $z):[\mathrm{M}-\mathrm{OH}]^{+}$calcd for $\mathrm{C}_{34} \mathrm{H}_{34} \mathrm{O}_{4}, 489.24$; found, 489.36. Compound 2f: white solid; mp $113-114{ }^{\circ} \mathrm{C} ;{ }^{1} \mathrm{H}$ NMR $(400 \mathrm{MHz}$, DMSO- $\left.d_{6}\right) \delta 7.48-7.41(\mathrm{~m}, 3 \mathrm{H}), 7.17(\mathrm{~d}, J=1.7 \mathrm{~Hz}, 1 \mathrm{H}), 7.03(\mathrm{~d}, J$ $=7.8 \mathrm{~Hz}, 1 \mathrm{H}), 6.95-6.99(\mathrm{~m}, 6 \mathrm{H}), 6.77(\mathrm{~d}, J=8.8 \mathrm{~Hz}, 4 \mathrm{H}), 6.64(\mathrm{~d}$, $J=8.7 \mathrm{~Hz}, 2 \mathrm{H}), 6.55(\mathrm{~d}, J=8.7 \mathrm{~Hz}, 2 \mathrm{H}), 5.76(\mathrm{~s}, 1 \mathrm{H}), 3.78(\mathrm{~s}, 3 \mathrm{H})$, $3.72(\mathrm{~s}, 6 \mathrm{H}), 3.67(\mathrm{~s}, 3 \mathrm{H}) ;{ }^{13} \mathrm{C}$ NMR (101 MHz, DMSO- $\left.d_{6}\right)$ $\delta 159.54,157.69,157.31,146.30,142.35,139.86,134.99,133.21$, 132.94, 131.57, 130.02, 129.47, 128.87, 120.18, 114.36, 114.04, 112.66, 111.94, 89.35, 88.05, 80.72, 55.26, 54.99, 54.90. HRMS (ESI) $(\mathrm{m} / \mathrm{z}):[\mathrm{M}-\mathrm{OH}]^{+}$calcd for $\mathrm{C}_{37} \mathrm{H}_{32} \mathrm{O}_{5}, 539.2222$; found, 539.2209 .

3.1.17. 4-((2-(Hydroxybis(4-methoxyphenyl)methyl)-4'methoxy-[1,1'-biphenyl]-4-yl)ethynyl)phenol (2g); $\quad 2^{\prime}$-(hydroxybis(4-methoxyphenyl)methyl)-4'-((4-hydroxyphenyl)ethynyl)[1,1'-biphenyl]-4-ol (2h). Compound 2e (139.1 mg, $0.25 \mathrm{mmol})$ was dissolved in $2 \mathrm{~mL}$ dry dichloromethane in a $10 \mathrm{~mL}$ chicken heart flask. Then the reaction mixture was stirred at $-83^{\circ} \mathrm{C}$ and boron tribromide $(140 \mu \mathrm{L}, 1.48 \mathrm{mmol})$ was added. After being stirred for 1 hour, $5 \mathrm{~mL}$ diethyl ether was added. The reaction mixture was stirred for $20 \mathrm{~min}$ and saturated sodium bicarbonate solution was slowly added. Then the reaction mixture was diluted with ethyl acetate and washed with saturated brine. The combined extract was dried by anhydrous sodium sulfate. Ethyl acetate was evaporated under vacuum. The residue was purified by silica gel chromatography to afford compound $2 \mathrm{~g}$ $(40.6 \mathrm{mg}, 30 \%)$ and compound $2 \mathbf{h}(66.0 \mathrm{mg}, 50 \%)$. The purity of the two compounds was detected by analytical HPLC to be over 95\%. Compound 2g: pink solid; mp 199-201 ${ }^{\circ} \mathrm{C} ;{ }^{1} \mathrm{H}$ NMR (400 MHz, acetone- $\left.d_{6}\right) \delta 8.79(\mathrm{~s}, 1 \mathrm{H}), 7.44(\mathrm{dd}, J=7.8,1.5 \mathrm{~Hz}, 1 \mathrm{H})$, 
$7.34(\mathrm{~d}, J=8.5 \mathrm{~Hz}, 2 \mathrm{H}), 7.09-7.11(\mathrm{~m}, 2 \mathrm{H}), 7.06(\mathrm{~d}, J=8.8 \mathrm{~Hz}$, $4 \mathrm{H}), 6.82-6.86(\mathrm{~m}, 6 \mathrm{H}), 6.68-6.74(\mathrm{~m}, 4 \mathrm{H}), 3.87(\mathrm{~s}, 1 \mathrm{H}), 3.79(\mathrm{~s}$, $6 \mathrm{H}), 3.76(\mathrm{~s}, 3 \mathrm{H}) ;{ }^{13} \mathrm{C} \mathrm{NMR}\left(101 \mathrm{MHz}\right.$, acetone- $\left.d_{6}\right) \delta$ 158.67, 158.65, 157.93, 146.40, 141.46, 139.97, 134.23, 133.13, 133.02, 132.11, 130.40, 129.59, 129.10, 121.43, 115.60, 113.74, 112.80, 89.68, 87.29, 82.03, 54.58. HRMS (ESI) $(\mathrm{m} / \mathrm{z}):[\mathrm{M}-\mathrm{H}]^{-}$calcd for $\mathrm{C}_{36} \mathrm{H}_{30} \mathrm{O}_{5}$, 541.2020; found, 541.2011. Compound 2h: pink solid; mp $119-121{ }^{\circ} \mathrm{C} ;{ }^{1} \mathrm{H}$ NMR $\left(400 \mathrm{MHz}\right.$, acetone- $\left.d_{6}\right) \delta 8.76(\mathrm{~s}$, $1 \mathrm{H}), 8.37$ (s, 1H), $7.43(\mathrm{~d}, J=8.3 \mathrm{~Hz}, 1 \mathrm{H}), 7.33(\mathrm{~d}, J=8.5 \mathrm{~Hz}, 2 \mathrm{H})$, 7.05-7.11 (m, 6H), 6.83-6.86 (m, 6H), $6.64(\mathrm{q}, J=8.7 \mathrm{~Hz}, 4 \mathrm{H})$, $3.78(\mathrm{~s}, 6 \mathrm{H}), 3.75(\mathrm{~s}, 1 \mathrm{H}) ;{ }^{13} \mathrm{C}$ NMR $\left(101 \mathrm{MHz}\right.$, acetone- $\left.d_{6}\right)$ $\delta 158.70,157.90,156.46,146.40,141.52$, 140.03, 133.17, 133.01, $132.87,132.13,130.50,129.59,129.09,121.35,115.60,114.43$, 113.77, 112.82, 89.65, 87.32, 82.17, 54.59. HRMS (ESI) $(\mathrm{m} / \mathrm{z})$ : [M $-\mathrm{H}]^{-}$calcd for $\mathrm{C}_{35} \mathrm{H}_{28} \mathrm{O}_{5}, 527.1864$; found, 527.1866.

3.1.18. 7-((4-Hydroxyphenyl)ethynyl)-9,9-bis(4-methoxyphenyl)-9H-fluoren-2-ol (2i). Compound 2e (155.7 mg, 0.28 mmol) was dissolved in $2 \mathrm{~mL}$ dry dichloromethane in a $10 \mathrm{~mL}$ chicken heart flask. Then the reaction mixture was stirred in an ice water bath and boron tribromide $(110 \mu \mathrm{L}, 1.16 \mathrm{mmol})$ was added. After being stirred for $30 \mathrm{~min}, 5 \mathrm{~mL}$ diethyl ether was added. The reaction mixture was stirred for $20 \mathrm{~min}$ and saturated sodium bicarbonate solution was slowly added. Then the reaction mixture was diluted with ethyl acetate and washed with saturated brine. The combined extract was dried by anhydrous sodium sulfate. Ethyl acetate was evaporated under vacuum. The residue was purified by silica gel chromatography to afford compound $2 \mathbf{i}$ (38.8 mg, 27\%). White solid; mp $125-127{ }^{\circ} \mathrm{C}$; the purity of the compound was detected by analytical HPLC to be over 95\%. ${ }^{1} \mathrm{H}$ NMR (400 MHz, acetone- $\left.d_{6}\right) \delta 8.75(\mathrm{~s}, 1 \mathrm{H}), 8.53(\mathrm{~s}$, 1H), 7.71-7.75 (m, 2H), $7.46(\mathrm{~d}, J=8.1 \mathrm{~Hz}, 2 \mathrm{H}), 7.37$ (d, $J=$ $8.5 \mathrm{~Hz}, 2 \mathrm{H}), 7.12(\mathrm{~d}, J=8.8 \mathrm{~Hz}, 4 \mathrm{H}), 6.91-6.80(\mathrm{~m}, 8 \mathrm{H}), 3.74(\mathrm{~s}$, $6 \mathrm{H}) ;{ }^{13} \mathrm{C}$ NMR (101 MHz, acetone- $\left.d_{6}\right) \delta 158.61,157.97,157.77$, 154.32, 151.69, 140.25, 137.69, 132.94, 130.90, 130.68, 129.01, 128.52, 121.54, 121.04, 119.21, 115.58, 115.05, 114.12, 113.57, 113.02, 89.44, 88.09, 63.93, 54.56. HRMS (ESI) $(m / z):[M-H]^{-}$ calcd for $\mathrm{C}_{35} \mathrm{H}_{26} \mathrm{O}_{4}, 509.1758$; found, 509.1753 .

3.1.19. 4-((4'-Hydroxy-4-((4-hydroxyphenyl)ethynyl)-[1,1'biphenyl]-2-yl)(4-methoxyphenyl)methylene)cyclohexa-2,5-dien1-one (2j). Compound $2 \mathrm{e}(2.23 \mathrm{~g}, 4.0 \mathrm{mmol})$ was dissolved in $40 \mathrm{~mL}$ dry dichloromethane in a $250 \mathrm{~mL}$ round bottom flask. Then the reaction mixture was stirred at $-83{ }^{\circ} \mathrm{C}$ and boron tribromide $(7.6 \mathrm{~mL}, 80.39 \mathrm{mmol})$ was added. The temperature was slowly raised to $0{ }^{\circ} \mathrm{C}$. After being stirred for 4 hours, $30 \mathrm{~mL}$ diethyl ether was added. The reaction mixture was stirred for $20 \mathrm{~min}$ and saturated sodium bicarbonate solution was slowly added. Then the reaction mixture was diluted with ethyl acetate and washed with saturated brine. The combined extract was dried by anhydrous sodium sulfate. Ethyl acetate was evaporated under vacuum. The residue was purified by silica gel chromatography to afford compound $2 \mathbf{j}$ (943.4 mg, 48\%). Red solid; mp $191-193{ }^{\circ} \mathrm{C}$; the purity of the compound was detected by analytical HPLC to be over 95\%. ${ }^{1} \mathrm{H}$ NMR (400 MHz, DMSO$\left.d_{6}\right) \delta 10.01(\mathrm{~s}, 1 \mathrm{H}), 9.49(\mathrm{~s}, 1 \mathrm{H}), 7.66(\mathrm{dd}, J=8.0,1.6 \mathrm{~Hz}, 1 \mathrm{H}), 7.43$ $(\mathrm{d}, J=8.0 \mathrm{~Hz}, 1 \mathrm{H}), 7.41-7.33(\mathrm{~m}, 4 \mathrm{H}), 7.22(\mathrm{dd}, J=9.9,2.6 \mathrm{~Hz}$, $1 \mathrm{H}), 6.85-6.94(\mathrm{~m}, 6 \mathrm{H}), 6.81(\mathrm{~d}, J=8.6 \mathrm{~Hz}, 2 \mathrm{H}), 6.59$ (d, $J=$ $8.5 \mathrm{~Hz}, 2 \mathrm{H}$ ), 6.33 (dd, $J=10.0,1.9 \mathrm{~Hz}, 1 \mathrm{H}), 6.29$ (dd, $J=9.9$,
$2.0 \mathrm{~Hz}, 1 \mathrm{H}), 3.75(\mathrm{~s}, 3 \mathrm{H}) ;{ }^{13} \mathrm{C}$ NMR (101 MHz, DMSO- $\left.d_{6}\right) \delta 185.55$, 160.71 , 159.69, 158.27, 156.77, 142.07, 139.27, 138.91, 138.67, 134.37, 133.29, 133.09, 132.20, 130.86, 130.66, 129.96, 129.59, 128.95, 128.06, 127.90, 121.07, 115.78, 115.01, 113.62, 112.16, 91.18, 86.62, 55.36. HRMS (ESI) $(\mathrm{m} / \mathrm{z}):[\mathrm{M}-\mathrm{H}]^{-}$calcd for $\mathrm{C}_{34} \mathrm{H}_{24} \mathrm{O}_{4}, 495.1602$; found, 495.1618 .

\subsection{Biological assays}

3.2.1. MTT assay for cell growth inhibition. The inhibition of compounds $\mathbf{1 a}-\mathbf{1 e}$ and $\mathbf{2 a - 2 j}$ against MCF-7, HepG2, HeLa and L-O2 cells were evaluated using a standard MTT-based colorimetric assay. Three thousand corresponding cells per well were seeded into 96-well plates and incubated at $37^{\circ} \mathrm{C}, 5 \%$ $\mathrm{CO}_{2}$ for $24 \mathrm{~h}$. Then $100 \mu \mathrm{L}$ drug-containing medium with a series of concentration were dispensed into wells to maintain the final concentration as $100,50,25,12.5,6.25$ and $3.125 \mu \mathrm{M}$, respectively. Each concentration was in triplicate. After 48 hours of incubation, cell survival was determined by the addition of 20 $\mu \mathrm{L}$ MTT (Sigma-Aldrich, St. Louis, USA) work solution (5 mg $\mathrm{mL}^{-1}$ MTT dissolved in phosphate buffer solution). After postincubation at $37{ }^{\circ} \mathrm{C}$ for 4 hours, the medium was discarded followed by adding $150 \mu \mathrm{L}$ DMSO (Sigma-Aldrich, St. Louis, USA). The plates were then vortexed for $10 \mathrm{~min}$ for complete dissolution. The optical absorbance was measured at $570 \mathrm{~nm}$. The data represented the mean of three independent experiments in triplicate and were expressed as mean $\pm \mathrm{SD}$. The $\mathrm{IC}_{50}$ value was defined as the concentration at which $50 \%$ of the cells could survive.

3.2.2. Cell-based reporter assays for hypoxia inducible factor-1 (HIF-1) inhibition. HeLa cells expressing HREdependent firefly luciferase reporter construct (HRE-Luc) and constitutively expressing CMV-driven Renilla luciferase reporter with SureFECT transfection reagent were established with Cignal $^{\mathrm{TM}}$ Lenti Reporter (SABiosciences, Frederick, MD) according to the manufacturer's instructions. The consensus sequence of HRE was $5^{\prime}$-TACGTGCT- $3^{\prime}$ from the erythropoietin gene. Cells stably expressing the HRE-reporter gene were selected with puromycin. The cells were incubated for 12 hours with or without drugs under the normoxic or hypoxic condition $\left(1 \% \mathrm{O}_{2}\right)$. After incubation, the luciferase assay was performed using a Luciferase Assay System (Promega, Madison, WI) according to the manufacturer's instructions. The drug concentration required to inhibit the relative light units by $50 \%$ $\left(\mathrm{IC}_{50}\right)$ was determined from semi-logarithmic dose-response plots, and the results represent means $\pm \mathrm{SD}$ of triplicate samples.

\section{Conclusion}

In conclusion, we designed and synthesized a class of natural product-like biphenyl-containing diaryl acetylenes mimicking natural alkynyl phenols from the genus Selaginella. In MTT assay in cancer cells, compounds $1 \mathbf{c}, 2 \mathbf{d}, 2 \mathbf{g}, 2 \mathbf{h}, 2 \mathbf{i}$ and $2 \mathbf{j}$ exhibited potent cytotoxic activity. The evaluation of HIF-1 inhibitory activity demonstrated that all tested compounds exhibited moderate to good activities except $\mathbf{2 j}$. Compounds 1a, 
2f and $\mathbf{2 h}$ displayed high HIF-1 inhibitory activities and relatively low cytotoxicity, demonstrating their great potential as HIF-1 inhibitors. These results afford us a new strategy for the discovery of new HIF-1 inhibitors and anti-proliferative agents from natural or synthetic diaryl acetylene derivatives.

\section{Conflicts of interest}

There are no conflicts to declare.

\section{Acknowledgements}

This research was supported by the National Natural Science Foundation of China (Grant No. 21606036) and the Fundamental Research Funds for the Central Universities (DUT16RC(3)007, DUT18LK11).

\section{Notes and references}

1 C. Sergiu, Mini-Rev. Med. Chem., 2009, 9, 560-571.

2 Y. Xie, K. P. Xu, Z. X. Zou and G. S. Tan, Cent. South Pharm., 2017, 15, 129-142.

3 L. Zhang, Y. Liang, X. Wei and D. Cheng, J. Org. Chem., 2007, 72, 3921-3924.

4 Y. Cao, J. Chen, N. Tan, L. Oberer, T. Wagner, Y. Wu, G. Zeng, H. Yan and Q. Wang, Bioorg. Med. Chem. Lett., 2010, 20, 2456-2460.

5 Y. Cao, J. Chen, N. Tan, Y. Wu, J. Yang and Q. Wang, Magn. Reson. Med., 2010, 48, 656-659.

6 X. L. Cheng, S. C. Ma, J. D. Yu, S. Y. Yang, X. Y. Xiao, J. Y. Hu, Y. Lu, P. C. Shaw, P. H. But and R. C. Lin, Chem. Pharm. Bull., 2008, 7, 982-984.

7 K. P. Xu, H. Zou, Q. Tan, F. S. Li, J. F. Liu, H. L. Xiang, Z. X. Zou, H. P. Long, Y. J. Li and G. S. Tan, J. Asian Nat. Prod. Res., 2011, 13, 93-96.

8 K. Xu, H. Zou, G. Liu, H. Long, J. Li, F. Li, Z. Zou, J. Kuang, X. Xie and G. Tan, J. Asian Nat. Prod. Res., 2011, 13, 10511055.

9 G. G. Zhang, J. Ying, H. M. Zhang, E. L. Ma and X. Y. Sun, Planta Med., 2012, 78, 390-392.

10 C. Yang, Y. Shao, K. Li and W. Xia, Beilstein J. Org. Chem., 2012, 8, 1884-1889.

11 Y. Cao, Y. Yao, X. Huang, L. Oberer, T. Wagner, J. Guo, W. Gu, W. Liu, G. Lv, Y. Shen and J. Duan, Tetrahedron, 2015, 71, 1581-1587.

12 C. Yuan, Y. P. Wu and J. A. Duan, Acta Pharm. Sin., 2015, 50, 199-202.

13 K. Xu, J. Li, G. Zhu, X. He, F. Li, Z. Zou, L. Tan, F. Cheng and G. Tan, J. Asian Nat. Prod. Res., 2015, 17, 819.
14 P. Nguyen, B. Zhao, M. Y. Ali, J. Choi, D. Rhyu, B. Min and M. Woo, J. Nat. Prod., 2014, 78, 34-42.

15 P. Nguyen, D. Ji, Y. Han, J. Choi, D. Rhyu, B. Min and M. Woo, Bioorg. Med. Chem. Lett., 2015, 23, 3730-3737.

16 B. Zhu, T. Wang, L. Hou, H. Lv, A. Liu, P. Zeng and A. Li, Chem. Nat. Compd., 2016, 52, 624-627.

17 D. D. Le, D. H. Nguyen, B. T. Zhao, S. H. Seong, J. S. Choi, S. K. Kim, J. A. Kim, B. S. Min and M. H. Woo, Bioorg. Chem., 2017, 72, 273-281.

18 Q. Zhu, Y. Bao, Z. Zhang, J. Su, L. Shao and Q. Zhao, R. Soc. Open Sci., 2017, 4, 170352.

19 G. Tan, K. Xu, F. Li, C. Wang, T. Li, C. Hu, J. Shen, Y. Zhou and Y. Li, J. Asian Nat. Prod. Res., 2009, 11, 1001-1004.

20 X. Liu, H. Luo, Y. Huang, J. Bao, G. Tang, Y. Chen, J. Wang and S. Yin, Org. Lett., 2013, 16, 282-285.

21 B. S. Chinta and B. Baire, Org. Biomol. Chem., 2017, 28, 58576060.

22 Y. Huang, X. Liu, D. Wu, G. Tang, Z. Lai, X. Zheng, S. Yin and H. Luo, Biochem. Pharmacol., 2017, 130, 51-59.

23 R. Karmakar and D. Lee, Org. Lett., 2016, 18, 6105-6107.

24 M. J. Sowden and M. S. Sherburn, Org. Lett., 2017, 19, 636637.

25 J. S. Zhang, X. Liu, J. Weng, Y. Q. Guo, Q. J. Li, A. Ahmed, G. H. Tang and S. Yin, Org. Chem. Front., 2017, 4, 170-177.

26 X. Liu, H. Luo, Y. Huang, J. Bao, G. Tang, Y. Chen, J. Wang and S. Yin, Org. Lett., 2013, 16, 282-285.

27 C. Wang, C. Hu, K. Xu, G. Tan and Y. Li, J. Cardiovasc. Pharmacol., 2010, 55, 560-566.

28 J. Kim, C. Cho, B. Tai, S. Yang, G. Choi, J. Kang and Y. Kim, Molecules, 2015, 20, 21405-21414.

29 C. Wang, C. Hu, K. Xu, Q. Yuan, F. Li, H. Zou, G. Tan and Y. Li, Naunyn-Schmiedeberg's Arch. Pharmacol., 2010, 381, 73-81.

30 W. Zhang, Y. Xu, K. Xu, W. Wu, G. Tan, Y. Li and C. Hu, Eur. J. Pharmacol., 2012, 694, 60-68.

31 G. L. Semenza, Annu. Rev. Phytopathol., 2014, 9, 47-71.

32 K. Lisy and D. J. Peet, Cell Death Differ., 2008, 15, 642-649.

33 B. J. Moeller, Y. Cao, C. Y. Li and M. W. Dewhirst, Cancer Cell, 2004, 5, 429-441.

34 D. Bhattarai, X. Xu and K. Lee, Biochem. Syst. Ecol., 2018, 38, 1404-1442.

35 S. P. Shi, Y. Z. Wang, X. K. Zheng, W. S. Feng and P. F. Tu, Biochem. Syst. Ecol., 2012, 45, 151-154.

36 M. Sun, L. Su, J. Dong, L. Liu, Y. Zhou and S. Yin, Tetrahedron Lett., 2017, 58, 2433-2437.

37 G. N. Masoud and L. Wei, Acta Pharm. Sin. B, 2015, 5, 378389.

38 G. Z. Li, S. Azuma, H. Minegishi and H. Nakamura, J. Organomet. Chem., 2015, 798, 189-195. 